\title{
Verbal Interaction Types in Science Inquiry Activities by Group Size
}

\author{
Soomin Lim ${ }^{1}$, Kyung-Chan Park ${ }^{1}$, Minsu Ha ${ }^{2}$, Hyonyong Lee ${ }^{1}$, Youngshin Kim ${ }^{\text {* }}$ \\ ${ }^{1}$ Kyungpook National University, REPUBLIC OF KOREA \\ 2 Kangwon National University, REPUBLIC OF KOREA
}

Received 23 August 2018 - Revised 23 August 2018 - Accepted 16 September 2018

\begin{abstract}
The extant research on linguistic interactions in scientific inquiry has focused solely on the quantitative analysis of the verbal interactions among the students and poses limitations to investigating the internal characteristics of such interactions. This paper presents connections among the members of a student group based on its interaction patterns and size to find out the ideal size of a student group in order to allow the student to have optimum participate in the group interactions. In this regard, this study sought to analyze the patterns of verbal interaction that occur during inquiry activities using social network analysis (SNA). 144 first-grade middle school students in science class in South Korea were participated and organized into small groups with three to six members each, and the language network of the 32 small groups that were thus formed was analyzed. The conclusions of this study are as follows: (1) the groups of students formed in school for learning activities should consist of only three members each to avoid alienation among the members, and (2) in student groups with four or more members each, there are many participation-type interaction structures that can be used if there is a group leader. The interactions among students within small learning groups can allow them to fully understand other students' opinions which may otherwise not be very clear, and to solve a problem after considering all the opinions students have expressed, and support the effective learning by positive interactions among the members.
\end{abstract}

Keywords: group size, social network analysis, verbal interaction types

\section{INTRODUCTION}

Interaction is a necessary activity for human beings to connect ideas and knowledge building. The view is also supported by Vygotsky's social constructivism that suggests knowledge formed and acquired through active interactions with members of society, such as one's colleagues or adults, rather than through individual cognitive activities (Vygotsky, 1978). Through active interaction, students form knowledge and construct new ways of understanding in the process of exchanging opinions and negotiating with others (Howe, Rodgers, \& Tolmie, 1990; Palincsar, 1998). In addition, interaction not only helps reduce students' fear of expressing their opinions to induce active participation and helps develop their logical reasoning abilities but also contributes to knowledge formation and problem-solving (Lumpe \& Staver, 1995). Therefore, it can be said that interaction plays an important role in learning.

In addition, the interaction among the students constituting small groups formed for learning activities has advantages in that it allows the students to understand the otherwise unclear opinions of other students fully and to solve a problem after considering all the opinions expressed (Alexopoulou \& Driver, 1996; Johnson \& Johnson, 1985; Palinscar, 1998). Therefore, to learn effectively, it is essential to encourage active and positive interactions among the members of small student groups formed for learning activities.

(C) 2019 by the authors; licensee Modestum Ltd., UK. This article is an open access article distributed under the terms and conditions of the Creative Commons Attribution License (http://creativecommons.org/licenses/by/4.0/).

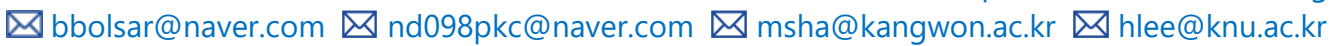




\section{Contribution of this paper to the literature}

- Provides linguistic interactions in scientific inquiry through the quantitative analysis of students' verbal interaction.

- Analyzes the patterns of verbal interaction that occur during inquiry activities using social network analysis (SNA).

- The findings of this study indicate that the groups of students formed in school for learning activities should consist of only three members each to avoid alienation among the members.

- In student groups with four or more members each, there are many participation-type interaction structures that can be used if there is a group leader.

- The interactions among students within small learning groups can allow them to fully understand other students' opinions.

In particular, inquiry activities, which are mainly used as methods of scientific learning, are processes for solving problems through suggestions from the members of the small groups formed for such inquiry activities; through the processes of acceptance, criticism, revision, and consultation among them; and through the learnercentered activities that they carry out, in which interactions are important (Driver, Newton, \& Osborne, 2000). Inquiry activities provide the members of the small student groups formed for such purposes with opportunities to actively and critically exchange various assertions and opinions among themselves; their importance to inquiry learning, which overcomes challenges through collaborative interactions within the small student groups, has been emphasized in the science curriculum (Ministry of Education, Science, and Technology, 2010). According to one report, the fewer the interactions among the members of small student groups formed for scientific inquiry activities, the more difficult it is for the students to improve their understanding of the subject matter being taken up (Nattiv, 1994). In other words, the quality of interaction among group members might be a strong predictor of students' learning outcomes in scientific inquiry activities (Cheng, Lam, \& Chan, 2008). Therefore, it can be said that the formation of small student groups is an important factor that should be considered when planning effective scientific inquiry activities, as it can allow active interactions to occur in such activities.

As the formation of efficient small student groups is important, there has been vigorous debate on how students should be grouped in learning (Cheng, Lam, \& Chan, 2008; Kyza, Constatinou, \& Spanoudis, 2011). Above all, various methods have been proposed to determine the appropriate size of a student group or the number of people who should constitute the group (Jang \& Kim, 2017). In this context, Brown (1993) said that the student groups formed for a scientific inquiry activity should consist of fewer than six members each, and Johnson and Johnson (1989) claimed that such groups should consist of two to six members each, but that a four-member group would be most effective. Slavin (1987) also showed that a two-, three-, and four-member students group would help improve the students' ability to conduct. The research results also showed that a three- or four-member student group would help improve the students' ability to conduct inquiries (Kim, 2009; Kim \& Kim, 2004). Most studies on the appropriate size of a student group formed for a scientific inquiry activity, however, dealt mainly with the relationship between the size of the group and the members' ability to conduct inquiries, and there is a dearth of research on the interaction patterns among the group members. Therefore, it is important to analyze the verbal interaction patterns among the group members according to the size of the group because this may provide additional clarity about why the size of a student group formed for an inquiry activity can influence the students' ability to conduct inquiries.

The interactions among students are mostly carried out using language, which is the outcome of personal thinking (Ernest, 1994; Hennessy, 1993). Many studies have been conducted to analyze the verbal interactions among the members of small student groups carrying out scientific inquiry activities (Anderson et al., 2001). However, most of these studies were based on the linguistic analysis framework and were limited to a quantitative analysis of the verbal interactions among the students, thereby posing limitations to identifying the internal characteristics of the interactions among the members of the small student groups in the inquiry process (Kim et al., 2017).

Recently, social network analysis (SNA) has been used to overcome the limitations above (Hansen, Shneiderman, \& Smith, 2009). SNA is a technology that quantitatively analyzes the interactions that occur among the members of a group when communication or information exchange takes place. It visualizes the interaction patterns of the group through a picture consisting of dots and lines (Derfel \& Sonnaughton, 2009; Storberg-Walker \& Gubbins, 2007).

It can be seen how each member of a small group is connected to the other members, or how all the members are related to one another. It helps in intuitively determining if any member plays a central role in the group or if there is an alienated member, and who the central or alienated member is (Kim et al., 2017). Kim and Kim (2015) analyzed the types of interactions occurring in inquiry activities through social network analysis. The study 
presented eight types of interactions shown by gifted students. Another study by Kim (2018) with general students presented 13 types of interactions including seven types of interactions with alienated students and six types of interactions with all students. The previous study analyzed only small groups of five students and found that some students could not join the interaction. Based on this result, they suggested the research questions on the sample size which allows all students to join the interaction (Kim \& Kim, 2015). Therefore, this study sought to analyze the characteristics of the interaction patterns of small groups of general students by adjusting the size of such groups. This would help determine the kind of connections present among the members of a small student group based on its interaction patterns and size and would indicate the ideal size of a small student group in order to allow the student members to participate meaningfully in the group interactions.

\section{METHODS}

\section{Participants}

The participants of this study were 180 first-grade (male 52.1\% and female $47.9 \%$ ) students in middle schools located in Daegu City in South Korea. The school in this study have a relatively higher academic achievement than other schools, and the students are highly motivated to study.

They were split up into small groups with three to four members each (70 students in the first grade of D Middle School) and small groups with five to six members each (110 students in the first grade of K Middle School). Of the 40 small groups, 8 cases were excluded from the analysis because the students turned off the recorder in the middle of the class or had trouble hearing due to the excessively loud background noise, or because the recorder's sound quality was not good enough for analysis purposes. Thus, 32 groups (144 people) were selected as analysis subjects. The small groups were made to consist of three to six members each based on the studies of Brown (1993) and Johnson and Johnson (1989). As these studies suggested that two- to six-member groups are expected to have only one type of interaction in a straight line, such groups were excluded from this study.

\section{Procedures}

The class was conducted in the general circumstances related to science classes in South Korea, in which the teacher lets the students identify the learning content, presents the learning goals to the students, and creates a classroom atmosphere that is conducive to learning. After the teacher explains the basic concepts to be learned and the experimental procedures and methods to be employed, the students proceed with the inquiry activities. In this study, the process that was employed in the students' inquiry activities was recorded for analysis. The content of the inquiry activities is as follows. The three- to four-member groups measured the specific heat capacities of metals like copper, iron, and aluminum through an experiment, and the five- to six-member groups performed the experiment on the photosynthesis of hydrilla.

\section{Data Collection and Analysis}

\section{Data collection}

In class, either a voice recorder or a cell phone with a recording function was used for recording purposes. Either one was set up at the center of the experimental desk for each small group to record its experimental inquiry activity. Camcorders were installed in front of the classroom, at an angle that could capture images of two groups or more per camcorder, so that the speaker could be identified if he/she could not be distinguished by voice. Before each class, the teacher informed the students that the recorded content would be used only for research purposes and then asked for the students' consent and cooperation.

To create a database containing information about each material, the recorded media files were transferred from a recorder or camcorder to a computer and then transcribed using Microsoft Word. However, cases in which the students' voices were not recorded because the students covered the recorder, or in which the students' voices could not be recognized due to the confused babble or background noise, were excluded from the transcription.

To evaluate the quality of our data, we assessed the validity of task used to measure students' interaction with three content experts in science education. Reliability of the measures was assessed using inter-rater reliability where the observer (in-service teacher) and experts as reliable rater agree with the official rating of performance which based on the frequency of utterances and responses made in the verbal interactions that occurred. By using Cohen's kappa measures, the result was exceeded by 0.8 (Cohen's kappa > 0.8). 


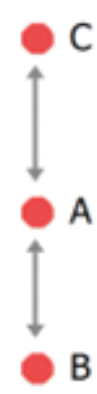

$B$

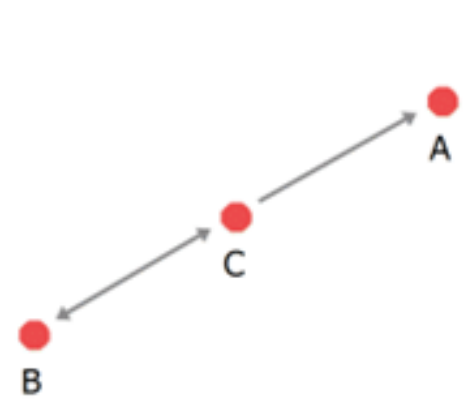

A

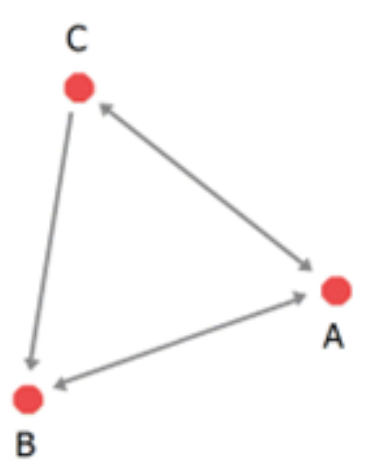

c. type $3-\mathrm{C}$

\title{
a. type 3-A
}

b. type $3-B$

\author{
c. type3-C
}

Figure 1. Interaction patterns that appeared in the three-member groups

\section{Data analysis}

The frequency (i.e., number of times of occurrence) of verbal interactions was measured based on the transcribed content. Only the verbal interactions among the members of each small group were recognized as interactions, and the soliloquies of individuals and the interactions with the teacher or with the members of another small group were excluded. The frequency of interaction was organized as the data of a matrix consisting of "person-to-person interaction."

To exhibit the structure of the interactions among the members of each small group, the data were converted to binary matrix data. The cut-off value that was used to convert the data to binary matrix data was based on the average interaction frequency in the previous research (Kim et al., 2017).

The converted binary matrix data were visualized using NetMiner 4, a software tool for SNA. NetMiner 4 identifies the utterance-response relationship of binary data and graphically depicts the structure of the interactions within small groups. In this study, the network data were visualized using the Spring-Eades algorithm, which can be utilized in NetMiner 4. The Spring-Eades algorithm has the advantage of being able to easily identify the interaction structure because it allows the nodes present in the matrix to be located close to one another and clarifies the relational structure of each node from a relative viewpoint (Choi \& Choi, 2010).

\section{RESULTS}

\section{Three-Member Groups}

Figure 1 shows the interaction patterns that appeared in the three-member groups. The most common interaction pattern type in the three-member groups was that showing a linear structure rather than a geometric figure (Figure 1a, b). This type appeared in six of the eight three-member groups, accounting for $75 \%$ of the total. In the linear-structure interaction pattern type, one student actively interacts with the two other students in a meaningful way, but the two other students do not show frequency of meaningful interaction with each other and are thus connected on both sides, while one student is in the center.

For the linear structures, all the four groups showed type 3A, in which the student playing a central role has a two-way (utterance-response) interaction with the other students. That is, in most cases, one leader led the inquiry activities while maintaining proper two-way interaction with the two other students. A look at the interactions in the small groups that showed the type-3A linear structure will indicate that student A alternately interacted with students B and C, and led the inquiry activity (Case 1).

(Case 1)

A: $200 \mathrm{~g}$ temperature change... originally at 27 degrees.

$\mathrm{C}$ : Hey, what is the temperature?

$\mathrm{A}: \mathrm{OO}$, the temperature is zero degrees?

B: Huh? 


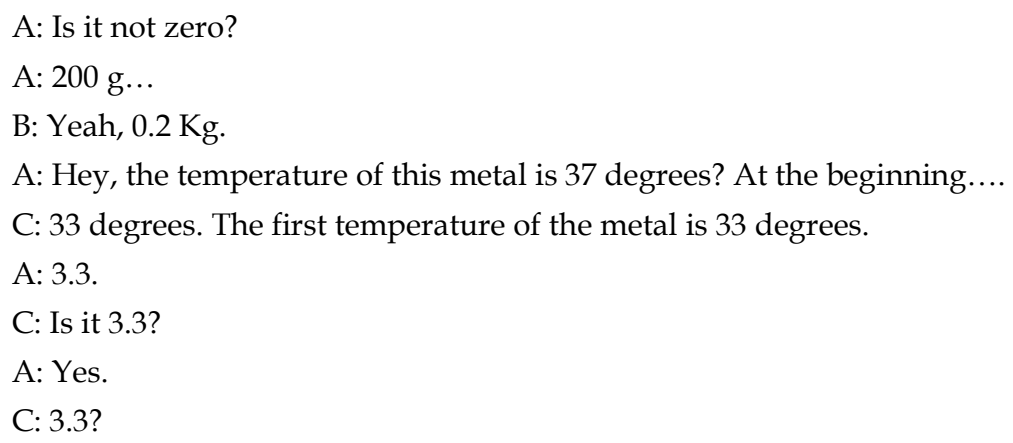

The two remaining groups out of the six groups that had a linear-structure interaction pattern type showed a structure in which a student playing a central role performs two-way (utterance-response) interaction with one student but shows one-way (utterance) interaction with the remaining student (Figure 1b). This structure appeared when the student forming a one-way interaction with the central student was passive or distracted in the course of the inquiry activity.

A look at the interactions in the small groups with a type-3B interaction structure will show that although student $C$ mentioned an irrelevant issue, the remaining two students began to concentrate on the inquiry activity again when student $\mathrm{C}$ also gave responses related to the inquiry activity. This suggests that if two members of a three-member group concentrate on the inquiry activity, they are carrying out, the remaining member cannot continue uttering irrelevant things by him/herself alone and will thus be forced to participate again in the inquiry activity. Therefore, it can be confirmed that even if one student is not active in an inquiry activity, a three-member group is likely to form a participation-type interaction structure rather than an alienation-type one as another student forms a response relationship with the student leader.

Another type of interaction structure appeared in two of the eight three-member groups, showing a triangle structure, where all the members of the group interacted with one another (Figure 1c). This type of interaction structure can be seen when all the members of a three-member group actively participate in the inquiry activity they are undertaking. This type also shows that the three students form interaction relationships with similar frequencies regarding both the frequency and directionality of their statements and that two students respond to one student's remarks at the same time.

Type 3-4 and 3-B showed a similar structure; but two were differentiated based on whether the center student has the two way interaction with other two students. In type 3-B, there were students who were not active in inquiry activities. The type of verbal interaction structure that appeared in the three-member groups was the participation type, in which there were no alienated members. This result is in line with those of studies (Kim \& Kim, 2004; Lee, 1995) that suggested that a small student group should be made to consist of only three members so that all the members could actively participate in the inquiry activity they were undertaking through a reduction of the number of alienated members.

It was also noticed that in five of the six groups that showed a leader-centered linear interaction structure, the student who acted as the leader was the first student to make an inquiry-related comment after the start of the inquiry activity. Although it was likely that the student at the center of the interaction made more comments than the other students and delivered the initial remarks, it was confirmed that taking the initiative in inquiry activities also positively affects the interactions in the group.

\section{Four-Member Groups}

Figure 2 shows the interaction patterns that appear in four-member groups. The most common type of interaction pattern among four-member groups shows a radial or similar form as one student takes the lead and the three other students interact with one another (Figure $\mathbf{2} \mathbf{a}, \mathbf{b}$ ). This type was found in four groups, accounting for $50 \%$ of the eight four-member groups. It was also confirmed that in this interaction pattern type, even if some students are passive in the inquiry activity, they have meaningful interactions with the student who acts as the leader, forming a participation-type interaction structure. Concerning the degree of centrality, the student positioned at the center has the highest value (3). Three of the four groups in this study that showed this interaction structure type had a complete radial structure (type 4A), with no interactions among the students except with the leader, and the remaining group exhibited a structure with a small triangle on one side (type 4B) as two of the three students (not the leader) interacted with each other. The interaction patterns of the small groups with the type- $4 \mathrm{~B}$ interaction structure also showed mostly similar aspects. Despite interactions between the two students who were not the leader, the leader was found to take the lead in the inquiry activity in the whole structure. This interaction structure type is different from type $4 \mathrm{~A}$ as some of the students constantly interact in pairs to create a meaningful 

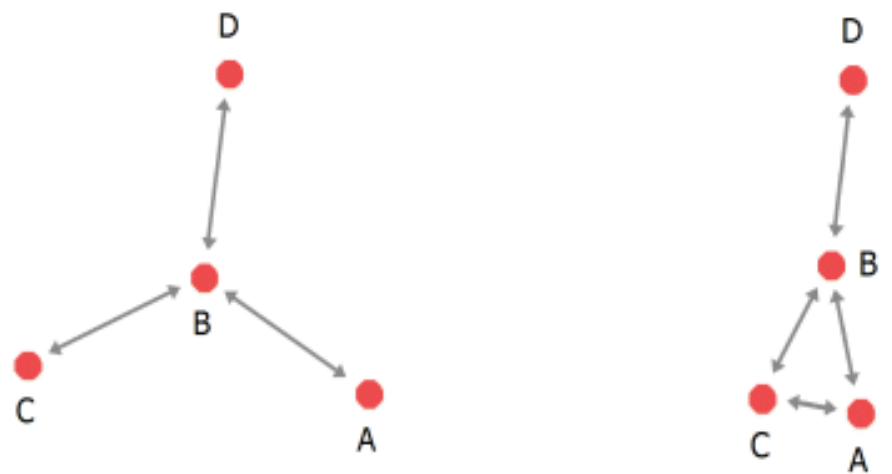

a. type $4-\mathrm{A}$

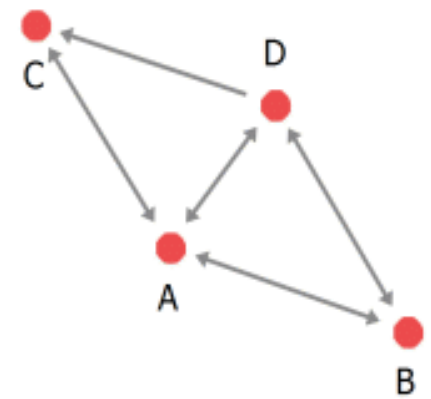

c. type $4-C$ b. type $4-B$

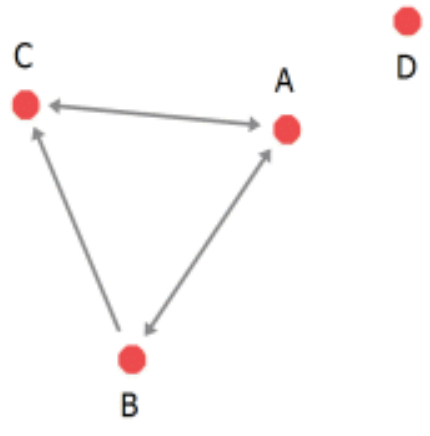

d. type 4-D

Figure 2. Interaction patterns that appear in four-member groups

interaction relationship. A look at the interaction example in Case 2 will reveal that student B, who played a central role in the inquiry activity, led the activity by helping the other members write their reports and informing them of matters requiring their attention, and the other students asked questions about the information on the inquiry activity that the leader gave them and about how to write a report. This can be said to be an example of a typical leader-centered interaction pattern.

(Case 2)

C: Is it $0.07 ?$

A: Yeah, kilogram.

B: OO, it is 0.07 kilograms here, not there.

$\mathrm{C}$ : What?

B: Don't use a ball-point, I told you.

C: Why?

B: Can you ask the teacher why?

C: Why?

D: Hey, where should I write it?

B: Here, 0.07 .

D: Mass. 0.07.

Two of the eight four-member groups in this study exhibited a diamond-shaped interaction structure as most of the students participated in the interaction in a balanced way. Although not all the students demonstrated 
interaction relationships, interaction relationships were formed between two students, except for one section (Figure 2c). Given that students D and A had the same degree of centrality (3), they led the inquiry activity, and the two other students actively followed; that is, two students acted as leaders.

Concerning the interaction patterns observed in the four-member groups, two groups exhibited a triangularbranched structure as one student was isolated (did not interact with anyone) and the three other students participated in the interaction on the whole. This type of interaction structure is formed when one student is alienated from the verbal interactions in the group due to his/her lack of linguistic participation in the inquiry activity compared with the three other students, and the rest of the students all form interaction relationships (Figure 2d).

In small groups of four students, there was a difference of types depending on whether there were students with centrality. The results showed that one student with centrality was Type 4-A and Type 4-B, two students with centrality was Type 4-C, and any student without centrality was Type 4-D. The difference between type 4-A and type 4-B was the presence of interaction between students. Types 4-B and 4-C were different depending on how many students with centrality interacted with each other.

In relation to the verbal interaction structures that appeared in the four-member groups, six of the eight groups (75\%) showed a participation-type structure, whereas the remaining two groups (25\%) showed an alienation-type structure. Unlike in the three-member groups, the alienation-type interaction structure began to appear in the fourmember groups. In contrast to the findings of Kang, Kim, and Noh (2000), however, which showed that the rate of the cases in which all the four students participated in the inquiry activity was about $10 \%$, a high proportion of the small groups $(75 \%)$ exhibited a participation-type interaction structure, in which all the members participated in the inquiry activity. In this regard, further analysis is needed to investigate the factors that determine the participation level of the small-group members in their inquiry activity.

\section{Five-Member Groups}

There were six types of interaction structures in the five-member groups in this study, as shown in Figure 3. The first type of interaction was a radial-shaped structure in which one student was alienated and the four other students engaged in interactions around the leader (Figure 3a). This type of interaction structure appeared in one group and showed one student having minimal verbal interactions with the others and thus being alienated, and the remaining four students building interaction relationships with one another around the student playing a central role.

The interaction case of a small group with the type-5A interaction structure showed that student B understood the inquiry process and told the others what to do next and that the other students got involved in the inquiry activity by relying on student B for information. As a result, student B came to build the interaction structure as a leader, with the highest degree of centrality (3) in this case. The next interaction structure type is similar to type 5A but is a structure that forms a small triangle as the leader, and the other students participate in the interactions (Figure $3 \mathbf{b}$ ). The conversations of the small groups that exhibited the type-5B interaction structure revealed that student $\mathrm{A}$, positioned at the center of the interaction structure, coordinated and directed the overall progress of the interaction activity, as was the case for student B in the small groups that exhibited the type-5A interaction structure. Students B and E received confirmation from student A about what they should do in the inquiry process, and student $C$ showed frequent interactions with student $E$ while following the directions of student $A$. Student $D$. However, made comments unrelated to the inquiry or engaged in too much self-talk, which made it difficult for him/ her to respond, thus failing to form an interaction relationship. 


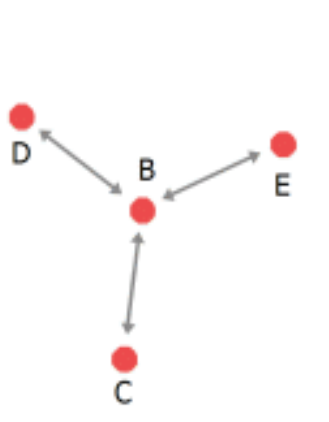

a. type 5-A

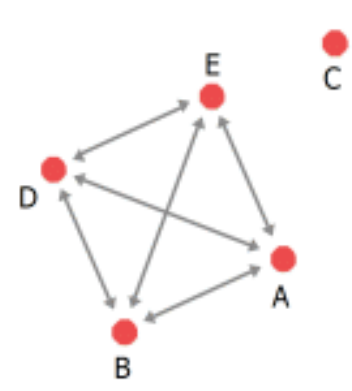

d. type 5-D
A

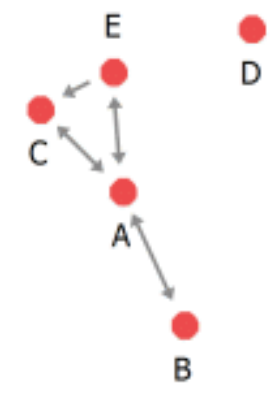

b. type $5-B$

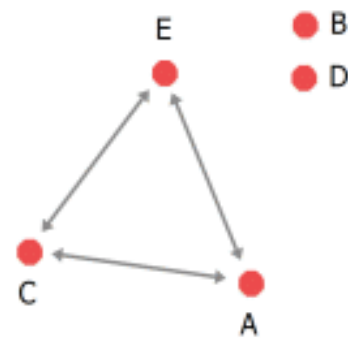

e. type 5-E

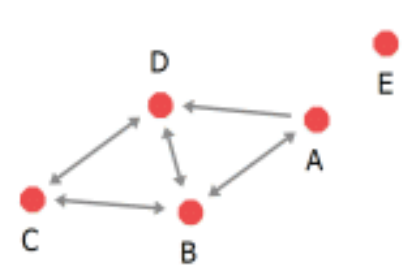

(1)

c. type $5-\mathrm{C}$

Figure 3. Interaction patterns that appear in five-member groups

In addition, there was a structure that showed overall interactions among the students. In this case, although one student was alienated, the remaining four students did not fully rely on the leader and interacted with one another in the course of their inquiry activity. This type of interaction occurs when one student fails to form an interaction relationship and is thus alienated, but the rest of the students interact indiscriminately with one another to form interaction relationships without a specific degree of centrality (Figure $3 c, d$ ).

This type of interaction structure can again be divided into type $5 \mathrm{C}$, in which the interaction structure that has four students participate in the interaction forms a diamond shape, and type $2 \mathrm{D}$, which shows a square shape. The difference between these two structures is that in the case of a square-shaped structure, four students have the same status as they all have a degree of centrality of 3, whereas in a diamond-shaped structure, two students have a degree of centrality of 3 , and two have a degree of centrality of 2 . A look at the structure of type $5 \mathrm{C}$ can confirm that almost all the students in the groups that exhibited such interaction structure interacted with one another, but no interaction occurred between students $\mathrm{A}$ and $\mathrm{C}$.

The interaction example in Case 3 of a small group exhibiting the type-5D interaction structure showed an aspect that makes it slightly different from the type-5C interaction structure. The most noticeable finding was that the frequency of asking questions or of carefully guessing word meanings was much higher than that of issuing claims or commands. Although student B showed a tendency to sort out and answer the other students' questions, the other students also actively interacted with one another. As a result, all the students except student $C$ came to achieve two-way (utterance-response) interaction.

(Case 3)

A: Well, why is there a thermometer?

B: Temperature, the temperature rises...

D: Does it come out at this time?

B: It comes out even at this time.

E: Alas! Turn it off after the light is turned on... You have to do it when the light starts flashing... 

C: Hey, did $\mathrm{OO}$ put this thing after cutting it?
B: Yes.
D: It seems that the temperature is gradually rising.
$\mathrm{B}$ : The temperature is going up.
A: It seems easy when two people are there.
$B$ : Yeah, it seems very easy.
D: Do you think the temperature goes up?
E: Well.... it's cold.
B: It's still cold.
A: Hey, put it at this point, not there.
$\mathrm{B}$ : Is it different at this point?
D: Different? I think it will be.

A: Maybe we should direct the light towards a different point?

D: Huh? Is it all right to put the thermometer here?

One of the eight five-member groups showed two students alienated and the remaining three students interacting to form a triangular interaction structure (Figure 3e). The type-5E interaction structure appeared in 9 of the 31 groups in the research conducted on five-member groups (Kim et al., 2017). Such research claimed that this type of interaction structure appears when no members encourage the alienated members to participate in the inquiry activity or lead them in a positive direction (Kim \& Kim, 2015).

While there were small groups with two alienated members, some small groups showed a participation-type interaction structure (Figure 3f). The interaction of these small groups exhibited a trapezoidal structure connected with three triangles. This interaction structure type is a kind of leader-centered structure in which all the other students interact with one another around student A; students B and E perform two-way interaction, and students $\mathrm{E}$ and $\mathrm{D}$, and students $\mathrm{D}$ and $\mathrm{C}$ perform the one-way interaction. In addition, the leader usually plays a central role and takes the initiative in the inquiry activity. In this leader-centered structure, the students usually engage in twoway interaction or spoken (utterance) interaction with the other students even in the case of one-way interaction. Student A is playing a central role in this small group, however, was observed to have response interactions with students $\mathrm{C}$ and $\mathrm{D}$.

Except for alienated students, the types 5-A, B, C and E were the same as those found in small groups of four. Type 5-D appeared only in a five-person group. This type of interaction occurred when four students interacted with each other and students interacted in two directions, such as types 5-E, 4-D, and 3-C.

The verbal interaction structures that appeared in the five-member groups in this study were all alienation-type interaction structures except for one group; as such, there were more alienation-type interactions than participationtype interactions in the five-member groups. It can be said that this is the same result as in the research that was conducted using the same method (Kim et al., 2017), which showed that the proportion of small groups that exhibited participation-type interaction structures was less than $30 \%$.

In addition, the research conducted on scientifically gifted students (Kim et al., 2017), found that the structure in which two of the five students in the group were alienated accounted for $29 \%$ of the total, but only one group showed an interaction structure with two alienated members in the present study conducted on general students. The students' participation in the inquiry activity was also higher than that in the previous studies, starting with the data on the groups with four or more members. In this regard, further research is needed to investigate the probable causes of these differences, such as the external factors (e.g., the level and personality of the students) or the methods of analyzing the research results.

\section{Six-Member Groups}

The interaction structures that appeared in the six-member groups in this study can be largely divided into four types, as shown in Figure 4. In four of the eight six-member groups, accounting for 50\%, one student was alienated, and the five other students demonstrated the interaction structure with the shape of a webbed foot (Figure 4a). The interaction structure among the five students (except for the alienated student) took the shape of a rhombus, whereas the diamond shape was connected with the alienated student, as in the type-5C interaction structure, an interaction structure type that appears in five-member groups. Regarding the degree of centrality, student D seems to have played the most central role, interacting with the four other students, while student $C$ interacted with three students and led the inquiry activity together with student D. 


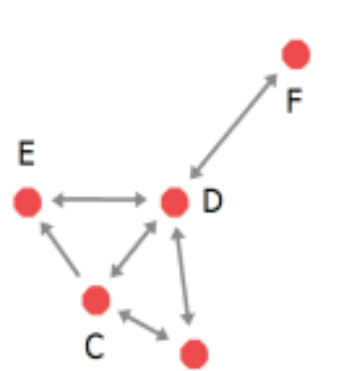

A

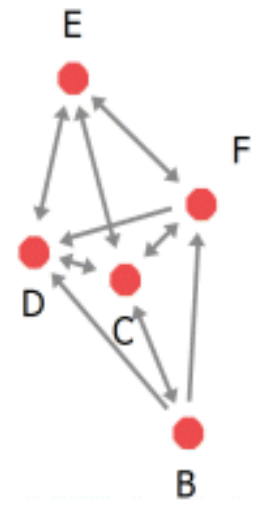

c. type $6-\mathrm{C}$

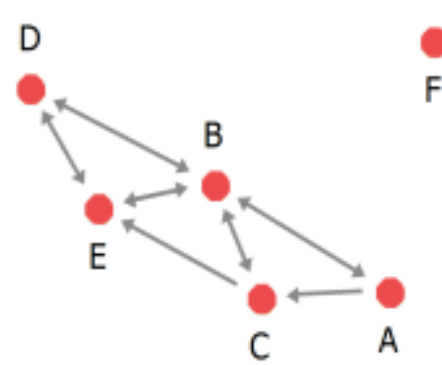

b. type 6-B

C
B

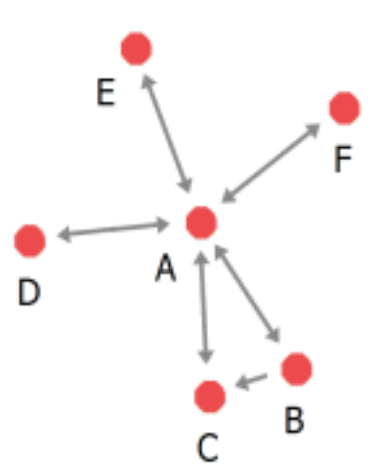

d. type 6-D

Figure 4. Interaction patterns that appear in six-member groups

Type 6B appeared in two small groups, and it showed a trapezoidal pattern of five students interacting with one another, with one alienated student (Figure $4 \mathbf{b}$ ). There was a leader-centered structure in which student B, who had a degree of centrality of 4, played a central role, except for one alienated student, as in the trapezoidal pattern in the interaction structure type found in the five-member groups, and all the members except student $\mathrm{F}$ participated in the inquiry activity around student B.

A look at the interaction example in Case 4 of a small group that showed the same interaction pattern as type $6 \mathrm{~B}$ will reveal that student $\mathrm{F}$ was alienated because he/she did not participate in the verbal interactions and instead concentrated on writing the group report, as the group's secretary. Student B looked confident and took the leadership role as a centrally positioned member of the group in terms of the interactions, and students C and E, who interacted with three students, also provided many comments and directed the other students to proceed with the inquiry activity as part of the efforts for direct involvement (Case 4).
(Case 4)
B: One
E: Put it down.
D: I'll put it down.
F: I'll be using it.
C: All right. I'll do it. Give it to me. Do not start yet.
B: Hey, no.... I'll do it, I....
C: No, I'll do it. No, stop it! 


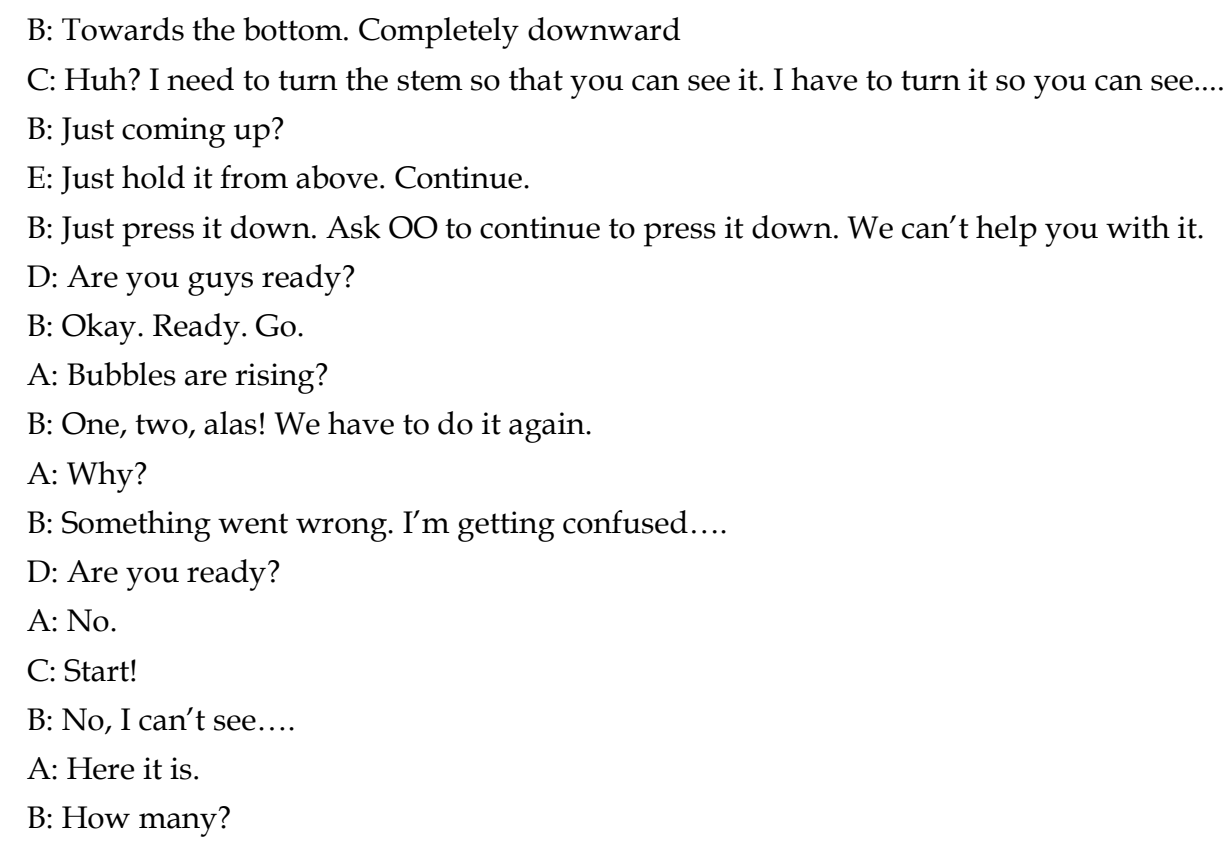

The third type of interaction in six-member groups was observed in one group, and it has a structure that shows a flat shape with straight sides as one student was alienated, and there were interactions among all the other students, except for the interaction between students E and B (Figure 4c). In this structure, three students have the same degree of centrality (4), and two other students (except alienated student A) also show active interactions. In addition, it can be predicted that as student D shows one-way interaction as a response relationship with two students, he/she will form an interaction relationship by responding to the opinions of others rather than presenting his/her opinions first.

The interaction structure to be introduced last shows an extreme one-person-centered interaction structure. More specifically, it has a radial structure in which student A, playing a central role, interacts with all the students, but there are almost no interactions among the other students, except for student A (Figure 6d).

In the small group of six students, several central students showed up, indicating that the leader of the group was unclear. In the absence of a leader, it is reported that interaction and cooperation between members are limited (Lee \& Chun, 2017) Therefore, if a leader was unclear in six small groups, it was difficult to direct members, provide information, or prioritize activities, etc. Therefore, it is considered inappropriate to comprise six members for the group's activities.

With respect to the interaction structures in the six-member groups, the alienation type appeared in seven groups, The ratio of participation to alienation-type interaction structures was the same as the ratio that appeared in the five-member groups. As one-on-one verbal interactions are most prevalent in small groups, the number of bystanders for a single verbal interaction increases as the group becomes bigger. In addition, although the same number of comments is made, the average number of interactions decreases as the small group becomes bigger, with an increasing number of members. For this reason, a lower interaction frequency, which is not significant in terms of the interaction structures, was recognized as an interaction relationship due to a low average interaction frequency or a low cut-off value.

In addition, the percentage of not being responded to was higher in the six-member groups than in the groups with fewer than five members. This is because as the group becomes bigger, the responsibility for answering the questions raised or responding to the opinions expressed is distributed. This result supports the results of the research conducted by Johnson and Johnson (1989), who pointed out the risk of free-riding and the difficulty of reaching a group consensus in small groups with more than five members.

\section{DISCUSSION}

So far, the verbal interaction structures that appeared in the small groups in this study according to the size of the group were analyzed. There were no alienated students in the three-member groups, and alienated students began to appear in the four-member groups. In the case of the four-member groups, there were alienated students in two of the eight groups; further, seven of the eight five- to six-member groups exhibited an alienation-type interaction structure. These results are consistent with those of the previous research that suggested that there would be free riders in groups with more than four members (Johnson \& Johnson, 1989; Park, 2006). 
The diversity of verbal interaction structures among middle school students leads to the expectation that various changes will occur during the process of inquiry activities. This in turn suggests that the interaction structures may vary depending on the strategies used and that teachers can encourage all the students constituting small groups to participate in the interactions within such groups. That is, the strategy of forming small groups will have to be used for general students who show a high percentage of participation in structured-learning-type interactions (Lee, Kang, \& Huh, 2009; Kim, 2006). It is also expected that studies will be conducted on teacher feedback from inquiry activities and on changes in interaction structures after teacher intervention or feedback. The study will analyze the impact of teacher intervention on students' interactions in autonomous inquiry classroom.

As alienated students appear in groups with more than four members, both divisions of roles and assignment of responsibilities are required in such groups (Kim \& Kim, 2004). This strategy has proven to be very effective in encouraging the students to actively participate in experiments and classes, and in improving their scientific inquiry abilities.

There was a significant difference in the percentage of participation- and alienation-type interactions according to the presence or absence of a leader in the four-member groups. Specifically, four groups exhibited participationtype interactions in the presence of a leader, but only two groups showed participation-type interactions in four group activities without a leader. Therefore, there is a need to designate a group leader when forming groups with more than four members each so that no student is alienated.

Therefore, it is expected that research will be added to ensure that the interaction type is stable according to the presence of the leader. It also suggests research on how changes in interaction types and students who are alienated participate in interactions when they are assigned roles.

On the other hand, a leader was positioned at the center of the verbal interaction structure through active utterances and responses to the current situation. This type of leader consistently checked the current situation, asked questions about the subsequent activities, and answered the questions raised by the other group members while exploring information. This student generally responded to the other students' remarks before the other group members did, resulting in poor verbal interactions among the other members.

Research has so far been limited to analyzing the types of interactions. In future studies, it is expected that studies will be conducted on the types of interactions by individual characteristics such as gender, the type of leader's communication style. It will also be necessary to add research into whether there is a difference in the ability to explore science depending on the type of interaction.

\section{CONCLUSIONS AND IMPLICATIONS}

\section{Conclusions}

This study was designed to analyze the interaction structures that occur in a small group according to the size of the group, by applying such interaction structures to scientific inquiry activities in general middle schools. The interaction structures were visualized based on the frequency of utterances and responses made in the verbal interactions that occurred in the course of the scientific inquiry activities. The relationships of the members of small groups were analyzed by identifying the characteristics of the interaction structures. Students' verbal interaction was found different depends on group size. The optimal number of members of a small group is three, to avoid alienated members. In the three-member groups in this study, the participation-type interaction structure appeared regardless of whether or not there was a leader actively leading the inquiry activity in the group and it minimize the number of people alienated from the group's inquiry activities. It also found that most of the student groups consisting of more than five members in this study were found to have alienated members. Furthermore, the result of study also found the ratio of proportion's participation- and alienation-type interaction structures also depend on presence or absence of a leader.

\section{Implications}

Three members are required for a group to avoid alienated members in a scientific inquiry activity. In this study, when a group consisted of three members, all three participated in the verbal interactions during the inquiry activity, regardless of the presence of a leader with centrality within the group. Therefore, the formation of threemember groups is expected to increase the level of participation in scientific inquiry activities.

In this study, when there were more than five students in a group, there were alienated members who did not participate in the inquiry activity, which suggests that fewer than four members are required for a group to conduct a scientific inquiry activity. Most of the small groups with more than five members in this study exhibited an alienation-type interaction structure as they could not attend to the members who did not participate in their group interactions despite a leader and interaction centrality. This is because, as the size of a group increases, the 
responsibility for answering the questions raised or responding to the opinions expressed is distributed, and thus, the likelihood that active interactions will occur is lowered.

The formation of four-member groups is suggested herein so that the members who can lead the inquiry activity in each group can be positioned to reduce the number of alienated students who will not participate in the inquiry activity. In this study, when a leader actively led the inquiry activity in a four-member group, he/she interacted with all three other members and thus helped create a participation-type interaction structure. In the absence of a leader, alienated members appeared in $50 \%$ of the small groups in this study. Therefore, it is expected that if an active and positive student who can play a leading role is positioned in each group, the number of alienated members in inquiry activities will be minimized.

\section{ACKNOWLEDGEMENT}

This research was supported by Basic Science Research Program through the National Research Foundation of Korea (NRF) funded by the Ministry of Education (NRF-2016R1D1A3B03934717).

\section{REFERENCES}

Alexopoulou, E., \& Driver, R. (1996). Small-Group Discussion in Physics: Peer Interaction Modes in Pairs and Fours. Journal of Research in Science Teaching, 33(10), 1099-1114. https://doi.org/10.1002/(SICI)10982736(199612)33:10<1099::AID-TEA4>3.0.CO;2-N

Anderson, R. C., Nguyen-Jahiel, K., McNurlen, B., Archodidou, A., Kim, S., Reznitskaya, A., \& Gilbert, L. (2001). The snowball phenomenon: Spread of ways of talking and ways of thinking across groups of children. Cognition and Instruction, 19(1), 1-46. https://doi.org/10.1207/S1532690XCI1901_1

Brown, B. B., Mounts, N., Lamborn, S. D., \& Steinberg, L. (1993). Parenting practices and peer group affiliation in adolescence. Child Development, 64(2), 467-482. https:// doi.org/10.2307/1131263

Cheng, R. W., Lam, S., \& Chan, J. C. (2008). When high achievers and low achievers work in the same group: The roles of group heterogeneity and processes in project-based learning. British Journal of Educational Psychology, 78, 205-221. https:/ / doi.org/10.1348/000709907X218160

Choi, Y., \& Choi, O. (2010). Analysis of the Operational Activities within the Social Enterprises Network. Korean Comparative Government Review (KCGR), 14(1). 63-76. https:/ / doi.org/10.18397/ kcgr.2010.14.1.63

Driver, R., Newton, P., \& Osborne, J. (2000). Establishing the norms of scientific argumentation in classroom. Science Education, 84(3), 287-312. https:/ / doi.org/10.1002/(SICI)1098-237X(200005)84:3<287::AID-SCE1>3.0.CO;2A

Ernest, P. (1994). Varieties of constructivism: Their metaphors, epistemologies and pedagogical implications. Hiroshima Journal of Mathematics Educations, 2, 1-14.

Hansen, D., Shneiderman, B., \& Smith, M. (2009). Analyzing social media networks: Learning by doing with NodeXL. Computing, 28(4), 1-47.

Hennessy, S. (1993). Situated cognition and cognitive apprenticeship: Implications for classroom learning. Studies in Science Education, 22(1), 1-41. https:/ / doi.org/10.1080/03057260608560019

Howe, C., Rodgers, C., \& Tolmie, A. (1990). Physics in the primary school: Peer interaction and the understanding of floating and sinking. European Journal of Psychology of Education, 5(4), 459-475. https://doi.org/10.1007/BF03173132

Jang, H., \& Kim, Y. (2017). An analysis of effect for grouping methods corresponding to ecological niche overlap of 7th graders' photosynthesis concepts. Journal of Science Education, 41(2), 195-212. https://doi.org/10.21796/jse.2017.41.2.195

Johnson, D. W., \& Johnson, R. T. (1985). Oral interaction in cooperative learning groups: Speaking, listening, and the nature of statements made by high-medium, and low-achieving students. Journal of Psychology, 119(2), 303-321. https:// doi.org/10.1080/00223980.1985.9915450

Johnson, D. W., \& Johnson, R. T. (1989). Cooperation and competition: Theory and research. NJ: International Book Company

Kang, S., Kim, H., \& Noh, T. (2000). Analysis of verbal interaction in small group discussion. Journal of the Korean Association for Research in Science Education, 20(3), 353-363.

Kim, J. (2006). Learning strategies for scientifically gifted children. The Journal of the Korean Society for the Gifted and Talented, 5, 19-32. 
Kim, J., \& Kim, B. (2004). The effects of group size on science process skills and attitudes toward science in middle school science class. Science Education Research Institute Korea National University of Education, 14(1), 68-82.

Kim, M., \& Kim, Y. (2015). An analysis of the verbal interaction patterns of science-gifted students in science inquiry activity. Journal of the Korean Association for Research in Science Education, 35(2), 333-342. https:/ / doi.org/10.14697/jkase.2015.35.2.0333

Kim, S. (2009). The effects of group size on mathematical achievement and mathematical attitude in the small group cooperative learning in mathematics classes. Unpublished Master thesis, Chungbook National University, Chungju, Korea.

Kim, Y. (2018). Analysis of verbal interaction types and stability in science inquiry activities in 7th grade students. Journal of Learner-Centered Curriculum and Instruction, 18(6), 563-584. https://doi.org/10.22251/jlcci.2018.18.6.563

Kim, Y., Kim, M., Ha, M., \& Lim, S. (2017). Analysis of stability in verbal interaction types of science-gifted students. EURASIA Journal of Mathematics Science and Technology Education, 13(6), 2441-2457. https:/ / doi.org/10.12973/eurasia.2017.01234a

Kyza, E. A., Constantinou, C. P., \& Spanoudis, G. (2011). Sixth graders' co-construction of explanations of a disturbance in an ecosystem: Exploring relationships between grouping, reflective scaffolding, and evidence-based explanations. International Journal of Science Education, 33(18), 2489-2525. https:/ / doi.org/10.1080/09500693.2010.550951

Lee, D. (1995). Human education and cooperative learning activity. Seoul: Sunghwasa.

Lee, J., Kang, S., \& Huh H. (2009). Establishment of teaching strategy through investigating scientific attitude, learning style, student's preferences of teaching style and learning environments of Korea science academy students. Journal of Gifted/Talented Education, 19(1), 141-162.

Lee, S., \& Chun, J. (2017). Analysis of argumentation on socio-scientific issue in middle school students' small group structure based on intimacy and leadership. Journal of Learner-Centered Curriculum and Instruction, 17(24), 343-368. https:// doi.org/10.22251/jlcci.2017.17.24.343

Lumpe, A. T., \& Staver, J. R. (1995). Peer collaboration and concept development: Learning about photosynthesis. Journal of Research in Science Teaching, 32(1), 71-98. https:/ / doi.org/10.1002/tea.3660320108

Ministry of Education, Science, and Technology (2010). Science curriculum. Seoul: Ministry of Education, Science, and Technology.

Nattiv, A. (1994). Helping behaviors and math achievement gain of students using cooperative learning. Elementary School Journal, 94(3), 285-297. https:/ / doi.org/10.1086/461767

Palinscar, A. S. (1998). Social constructivist perspectives on teaching and learning. Annual Review of Psychology, 49(1), 345-375. https://doi.org/10.1146/annurev.psych.49.1.345

Park, S. (2006). The effects of the group reward and cooperative skill training on the science achievement and learning motivation of elementary students. The Journal of the Korean Earth Science Society, 27(2), 121-129.

Slavin, R. E. (1987). Development and motivational perspectives on cooperative learning: A reconciliation. Child Development, 58, 1161-1167. https:// doi.org/10.2307/1130612

Storberg-Walker, J., \& Gubbins, C. (2007). Social networks as a conceptual and empirical tool to understand and "do" HRD. Advances in Developing Human Resources, 9(3), 291-310. https:/ / doi.org/10.1177/1523422306304071

Vygotsky, L. S. (1978). Mind in society: The development of higher psychological processes. Cambridge, Massachusetts: Harvard University Press.

\section{http://www.ejmste.com}

